\title{
A MUTAÇÃo CONSTITUCIONAL NO DIREITO PÚBLICO DO IMPÉRIO ALEMÃo: CONTRIBUIÇÕES DE LABAND E JELLINEK
}

\section{FLAVIO QUINAUD PEDRON ${ }^{1 *}$}

Resumo: Uma vez que o direito constitucional brasileiro continua a fazer uso do conceito de mutação constitucional, principalmente pelo STF, torna-se fundamental verificar a correção do emprego de tal instrumental teórico. $\mathrm{O}$ presente estudo tem por objetivo investigar as raízes históricas do conceito de mutação constitucional a partir do seu surgimento no contexto histórico do Império alemão. A partir disso, vamos poder identificar que a utilização do conceito pela teoria e pela prática brasileira se distanciam e se divorciam da construção original do direito constitucional alemão. Portanto, no Brasil, a mutação constitucional tem seu sentido esvaziado e transformado apenas em uma ferramenta retórica pelo STF.

Palavras-Chave: Mutação Constitucional; Direito Constitucional alemão; História do Direito.

Sumário: 1. Introdução; 2. A Contribuição de Paul Laband para uma teoria da mutação constitucional; 3. A mutação constitucional em Georg Jellinek; 4. Conclusão. Referências Bibliográficas.

\section{INTRODUÇÃO}

Ao longo da história da jurisprudência do STF, vamos encontrar diversas menções à teoria da mutação constitucional, inclusive sendo ratio decidendi mais frequente para os votos de ministros como Gilmar Mendes, Eros Grau, Luis Roberto Barroso.

Assim, cabe-nos indagar: o que é uma mutação constitucional?

Afinal, é comum que a dogmática constitucional brasileira responda que a mutação constitucional é uma mudança de interpretação de uma norma da Constituição, que faz com que um mesmo texto permaneça intacto enquanto o seu sentido, o conteúdo normativo, passa por uma alteração.

Ainda que a mutação por interpretação seja a mais popularmente conhecida forma, ela não é a única. Dau-Lin (1998, p. 31) sistematizando o conceito, apresentará outras possibilidades que

\footnotetext{
1." Doutor e Mestre em Direito pela UFMG. Professor Adjunto do Mestrado em Direito da UniFG (Bahia). Professor Adjunto da PUC-Minas (Graduação e Pós-graduação). Professor Titular do IBMEC. Membro da Associação Brasileira de Direito Processual Constitucional (ABDPC). Membro do Instituto Brasilerio de Direito Processual (IBDP). Membro da Rede Brasileira de Direito e Literatura. Advogado. E-mail: flavio@pedronadvogados.com.br.
} 
podem também ser chamadas de mutação constitucional; inclusive, o jurista chinês é o primeiro a identificar a possibilidade mutações inconstitucionais.

Contudo, se um olhar mais verticalizado por lançado sobre os trabalhos dogmáticos sobre o tema, vê-se que a primeira ideia (a da mutação por interpretação) se popularizou tanto, que é aceita naturalmente pelos juristas nacionais, ficando um conceito obscurecido pela sua falta de explicação e de reflexão.

Tal falta de rigor e de tratamento adequando sobre o conceito acaba prejudicando uma compreensão adequada do mesmo; e mais, acaba por deixar escapar a vista questões importantes, como legitimidade ou titularidade para constatar ou criar uma mutação constitucional.

É a partir desse pano de fundo que se justifica a presente pesquisa.

A mesma, portanto, assume como escopo investigar as raízes históricas do conceito de mutação constitucional. A partir de uma revisão da literatura, e usando de uma metodologia historiográfica, busca-se reconstruir o surgimento e o desenvolvimento do conceito de mutação constitucional em seu "berço", afinal suas primeiras formulações se dão no curso do Império Alemão, sendo que se registra que os dois primeiros juristas e trabalhar com tal conceito são Laband e Jellinek, que de maneira particular reconstroem o conceito de mutação constitucional a partir de premissas bem distantes.

Alertamos que escaparia do escopo do presente trabalho promover um estudo mais verticalizando, dialogando com todos os autores da teoria constitucional (alemã, espanhola, brasileira, etc.) acerca do tema, bem como demonstrando seus usos pelos Judiciários ao longo do mundo.

Nossa proposta, então, limita-se a apresentar o contexto que conduziu quer a Laband (2), quer a Jellinek (3) apensar - ainda que por matrizes distintas - uma teoria da mutação constitucional.

\section{A CONTRIBUIÇÃO DE PAUL LABAND PARA UMA TEORIA DA MUTAÇÃO CONSTITUCIONAL.}

A base central das constituições dos Estados alemães anteriormente à unificação - após meio século da invasão napoleônica - estava na existência do chamado princípio monárquico, que determinava que o monarca fosse o titular do poder soberano. A opção por uma constituição representava, então, uma opção do monarca em se autolimitar (STOLLEIS, 2001, p.62; CARVALHO NETTO, 1992, p.156-157), e, desde os seus preâmbulos, ${ }^{2}$ pode-se constatar que o

\footnotetext{
2 "The preamble to the 1850 Prussian constitution, for example, declared: 'We, Frederick William, King of Prussia by the Grace of God, let it be kwon and decreed that We [...] have definitively established the Constitution in agreement with both chambers"” (CALDWELL, 1997, p.16) Tradução livre: "O Preâmbulo da Constituição
} 
princípio monárquico permaneceu em sua lógica interna. Como consequência, tinha-se um sistema instável, que continuava a atribuir ao monarca a vontade subjetiva da Constituição (CALDWELL, 1997, p.16). Formalmente, pode-se observar que o monarca tinha o poder de reunir corpos representativos e, segundo a Constituição, mesmo as deliberações, os órgãos sobre liberdade, propriedade e, até mesmo, sobre o orçamento, estavam submetidos à sanção absoluta do monarca. Além disso, as forças armadas também estavam sob o comando solitário do monarca (CALDWELL, 1997, p.17). Com a hipertrofia da estrutura burocrática do Estado, conflitos envolvendo os gastos públicos e os limites orçamentários tornaram-se evidentes. Mesmo assim, o Estado não poderia suspender a Constituição.

Mas isso não impedia, como observa Jouanjan (2001, p.7), que o termo Rechtsstaat fosse empregado no sentido de representar uma limitação do Poder do Estado pelo Direito. Todavia, a teoria constitucional alemã no século XIX se apresentava muito mais comprometida com a ideia de criar mecanismos e teorias voltadas para impedir ou limitar o impacto do constitucionalismo moderno na dinâmica política do Império, que em defender a necessidade de promulgação de uma Constituição a partir da soberania popular. É por isso mesmo que toda a construção do Direito Constitucional nesse momento histórico levou em consideração tal "princípio monárquico". Isso significa que o monarca foi colocado em posição de centralidade, representando a unidade do Estado e, com isso, os direitos fundamentais foram reduzidos a um catálogo de suas dádivas bondosas, bem como o Parlamento foi transformado em uma simples "comissão legislativa" (MAIA, 2010:53).

A Revolução de 1848 tinha por objetivo a criação de um Estado cuja base estaria na soberania popular, e não em uma monarquia constitucional. Mas, com o fracasso da revolução, todos os Estados que até o momento estavam sem uma constituição, passaram a adotar o modelo de uma monarquia constitucional (CAENEGEM, 1996, p.267). Na Prússia, a Constituição de 1848 foi substituída pela Carta de 1850, imposta por Frederico Guilherme IV, que, apesar de garantir mais poderes para o Landtag, dava a ele o controle das forças armadas, o poder de pactuar tratados e de declarar guerra e paz, além de torná-lo imune contra processos jurisdicionais. Diferentemente, o instituto da responsabilidade ministerial dotava o chanceler de responsabilidade pelas ações do Executivo, que era monitorado pelo Legislativo, e tinha poucos mecanismos de pressão, mas sua aprovação era exigida para a elaboração de todas as leis, inclusive as referentes ao orçamento (CALDWELL, 1997, p.17). saber e declaro que Nós [...] definitivamente outorgamos a Constituição em concordância com ambas as Casas". 
Nos primeiros anos de 1860, assume como novo monarca da Prússia Guilherme I, que introduz um conjunto de normas voltadas ao aumento de fundos para expedientes militares. Dentro das propostas, estava o aumento do tempo do serviço militar obrigatório de dois para três anos. A maioria liberal dentro do Landtag discordou das medidas por argumentos políticos e financeiros; acreditava que o aumento do serviço militar pudesse servir como medida de educação dos cidadãos para o aumento do respeito ao Estado autoritário (CALDWELL, 1997, p.18). Como reação, o Landtag aprovou um projeto exigindo que o orçamento militar fosse discriminado linha a linha. Em resposta, o princípio monárquico veio à tona. $\mathrm{O}$ monarca dissolveu o Landtag, mas a crise não foi solucionada, pois os novos eleitos representavam uma maioria ainda mais extensa de opositores.

A solução para a salvaguarda da Coroa veio na nomeação de Bismarck como PrimeiroMinistro prussiano. Para Bismarck, a Constituição não apresentava nenhuma saída jurídica para o conflito, logo, a solução voltava-se para o reconhecimento de que a Coroa representava uma entidade prévia e maior que a própria Constituição, devendo ela solucionar o vácuo normativo (CALDWELL, 1997, p.18). Além do mais, o Monarca deveria administrar o Estado, ainda que um orçamento não fosse formalmente aprovado. Em resposta, os liberais arguiram que o Monarca tinha de se submeter à Constituição. Diante do impasse, Bismarck determinou que o orçamento do ano anterior fosse aplicado até a aprovação do novo. Com essa medida, ele evitou levar o conflito às últimas raias.

O sucesso militar de Bismarck foi outro importante fator para colocar fim ao conflito. Em 1864, tropas prussianas e austríacas atacaram a Dinamarca pelo domínio de territórios germanofalantes sob poder dos dinamarqueses. Em 1866, foi a vez da Prússia atacar a Áustria em razão de conflitos acerca de como seriam esses territórios governados. Com a vitória prussiana, os Estados do norte alemão foram postos sob o regime de uma monarquia constitucional. Mais uma vez, o prestígio de Bismarck aumentou, inclusive permitindo a aprovação retroativa do orçamento, pondo fim à crise. Mas tal quadro acabou por encobrir um problema: com a aprovação, houve por fim o reconhecimento da possibilidade do Landtag controlar o orçamento público. Assim, o conflito não fora suficientemente solucionado, mas apenas adiado para outro momento (CALDWELL, 1997, p.19).

Laband (2007) publica o seu texto analisando o conflito em 1870, bem às vésperas da unificação. Com isso, ele oferecerá uma metodologia de compreensão da Constituição que se pretende "científica", justamente por excluir qualquer aspecto não jurídico do seu discurso, como lembra Verdú (2006, p.02). As discussões políticas, principalmente na concepção de Laband, foram responsáveis por obscurecer e por agravar o debate sobre a lei orçamentária. Analisando tanto o artigo 62 da Constituição Prussiana, que afirmava que a função legislativa era exercida 
conjuntamente pelo Landtag e pelo Monarca, e o artigo 99, que definia a lei orçamentária como uma lei, Laband (2007, p.07; 2007, p.22) entendia que o sentido aqui de lei, seria apenas formal, uma vez que, na realidade, sua verdadeira natureza seria a de uma decisão administrativa. Assim, ao invés de ela conter regras jurídicas, seria concernente aos assuntos de economia e de administração pública (LABAND, 2007, p.171). Como consequência, as questões do orçamento interessavam mais ao Executivo que ao Legislativo, razão pela qual deveriam ser deixadas para o Monarca decidir, sendo a aprovação pelo Landtag apenas uma formalidade constitucional (CALDWELL, 1997, p.20).

A Constituição Imperial de 1871 surge na história alemã do século XIX marcando um longo e tortuoso processo de unificação. Segundo Sánchez Urrutia (2000, p.106), tal unificação somente foi possibilitada pela dissolução da rivalidade entre Prússia e Áustria, a favor da primeira e com a exclusão da segunda.

A organização da Federação alemã trazia em seu interior vinte e cinco Estados-membros com grandes distinções internas. Carvalho Netto (1992, p.155) aponta a existência, inclusive, de três Repúblicas na forma de cidades livres (Brema, Hamburgo e Lubeca); sendo as outras, Monarquias, organizadas em Reinos (Prússia, Baviera, Saxônia e Würtemberg), Grão-Ducados (Baden, Axia, Mecklemburg-Schwerin, Saxônia-Weimar-Eisennack, Mecklemburg-Strelitz e Oldemburg), Ducados (Brünswick-Lüneburg, Saxônia-Meiningen, Saxônia-Altemburg, SaxôniaCoburgo e Gotha e Anhalt), Principados (Schwarzburg-Sondeshausen, Hessen, SchwarzburgRudolfstadt, Waldeck, Reuss-Csreiz, Shaumburg-Lippe e Lippe) e a Alsácia-Lorena, como território do Império.

Os Estados, então, titularizavam, cada um, sua Constituição, sendo dotados de organização política própria, autonomia e direito de enviar e de receber embaixadores e de firmar pactos internacionais - nos limites do interesse local (CARVALHO NETTO, 1992, p.155; CAENEGEM, 1996, p.271).

Diante de um quadro de tamanha diversidade, um sistema de adaptação dos ordenamentos particulares ao sistema do Império acabou ficando ausente, o que provocou uma insegurança jurídica. Diferentemente do que se pode observar nos Estados Unidos, onde a Constituição foi compreendida, desde cedo, como um conjunto normativo dotado de uma relativa rigidez, a tradição europeia vivenciou uma etapa intermediária do constitucionalismo a partir da experiência de constituições flexíveis (SÁNCHEZ URRUTIA, 2000, p.107).

O texto da Constituição de 1871 preservava a dinâmica da Constituição Prussiana de 1850 e, dessa forma, o Bundesrat - formado por membros indicados pelos governos estaduais representava a Monarquia, sendo o Kaiser apenas o cabeça desse corpo coletivo. Era o Bundesrat, 
e não o Kaiser, o detentor do direito de sanção sobre os projetos de leis aprovados pelo Reichstag (LABAND, 1901, p.294-295; CALDWELL, 1997, p.23).

O Bundesrat era composto por deputados indicados pelos Estados-membros para representá-los e tinha competência para determinar que projetos de leis seriam levados à votação no Reichstag. O Bundesrat ainda tinha o poder de negar sanção - com pelo menos quatorze votos, dos cinquenta e oito votos totais - a qualquer projeto de mudança formal da Constituição de 1871; sendo que a Prússica possuía dezessete desses assentos.

Nas três primeiras décadas, tanto o Kaiser quanto o Reichstag buscaram nortear suas ações para evitar conflitos acerca da Constituição. O título de Kaiser era assumido pelo rei da Prússia, que também tinha o poder de indicar o chanceler, que era o cabeça do Bundesrat. Dentro desse quadro, fica claro que a principal finalidade do Bundesrat era barrar qualquer mudança que pudesse representar risco à perda da hegemonia prussiana (CALDWELL, 1997, p.27). O Kaiser tinha poderes para declarar guerra - com o consentimento do Bundesrat, mas, nesse caso, era dispensada a consulta do Reichstag -, representar a Alemanha no cenário internacional e comandar as forças armadas.

Dentro desse quadro maior, as publicações de Laband desempenharam um importante papel de conversação da unidade artificial que integrava a Federação no Império alemão. Como um membro da Escola alemã de Direito Público ${ }^{3}$ - que, segundo Jouanjan (2005, p.189-190), foi fundada por Gerber e Gierke - assentou as bases de uma perspectiva "científica" ao afirmar um pressuposto metodológico fundamental: a separação entre direito e política (JOUANJAN, 2001:29; KELLY, 2003:84). Nessa linha de raciocínio, o direito deveria ignorar os fenômenos políticos, fechando-se em si mesmo (JOUANJAN, 2005, p.192-193; 2002, p.23).

Como perspectiva teórica, Laband (1901) defende que a interpretação e a compreensão do Direito devem ocorrer sem as incursões de questões valorativas para manter a imparcialidade e a cientificidade do jurista. Desse modo, ele dispensa qualquer aspecto histórico, político ou filosófico (CALDWELL, 1997, p.15-16; JOUANJAN, 2005, p.193; 2002, p.23). Sua metodologia, portanto, reduzia os problemas de compreensão do Direito a uma análise lógico-gramatical do texto normativo, sem a utilização de qualquer aspecto axiológico. Além disso, entendia que havia uma conexão orgânica entre o Estado e a Nação, de modo que as normas e leis do Império eram

\footnotetext{
${ }^{3}$ Laband representa um dos nomes mais importantes do Direito Público alemão no curso do período do Império. Nascido em 1838, de origem judaica, em Breslau converteu-se ao protestantismo e iniciou sua carreira jurídica na década de 1860, a partir do Direito Privado. Na década seguinte, vai volta-se para o Direito Público, tornando-se professor na Universidade de Strasbourg e ganha destaque dentro da doutrina juspublicista alemã (JOUANJAN, 2005, p.189-190).
} 
expressão de uma "vontade do Estado", que também coincidia com a "vontade da sociedade" (LABAND, 1901, p.303-305).

Em sua leitura, a "vontade do Estado" é o princípio maior da ordem jurídica, sobrepondose, inclusive, à ordem constitucional (LABAND, 1901, p.306; CALDWELL, 1997, p.36; KELLY, 2003, p.87). Como consequência, defendia o primado da "vontade do Estado" sobre suas normas, principalmente porque, para ele, o Estado precedia todas as normas, inclusive a Constituição. ${ }^{4} \mathrm{O}$ Estado era o soberano (KELLY, 2003, p.87) e, por isso, os direitos fundamentais eram "dádivas" do Estado para seu povo, não atributos naturais de cada sujeito. Assim, era da "vontade do Estado" impor a si mesmo as limitações na forma de direito negativo.

Uma vez que a análise da dogmática jurídica não ultrapassaria as questões metajurídicas, a dimensão histórica dos direitos fundamentais passa sem problematização para Laband (KELLY, 2003, p.88) e igualmente a sua intencionalidade política. Logo, a dogmática jurídica acaba transformando-se num veículo de legitimação através do seu discurso dos atos do Estado. Toda a sua finalidade revela-se, portanto, na descrição das normas a partir dos textos normativos, ignorando intencionalmente qualquer outra questão que pudesse aparecer. Ou seja, a dogmática jurídica para Laband deveria ser "míope" para tudo aquilo que não fosse matéria exclusivamente jurídica. E, com isso, fecham-se as portas para uma discussão sobre a legitimidade e os limites dos atos estatais. Além do mais, a ação estatal identificava a incorporação da "vontade do Estado" e "da sociedade" como um elemento só, e, assim, o jurista não era autorizado a discuti-la, dada as suas feições metajurídicas. É importante, então, resgatar a lógica trazida por trás do antigo "princípio monárquico" que aqui parece ter adquirido uma "nova roupa" e um novo nome, mas funcionando com efetividade idêntica à lógica da Constituição Prussiana.

Diante disso, Laband (1901, p.314) rejeitava a ideia de um controle de constitucionalidade pelo Judiciário, uma vez que a este caberia apenas a atividade mecânica - e livre de qualquer juízo de valor - de aplicação do direito ao caso concreto. Intrinsecamente à ideia de um controle de constitucionalidade estaria a inevitável produção de decisões judiciais baseadas em questões de ordem política, o que, para ele, era inadmissível (LABAND, 1901, p.329).

Dessa forma, mesmo compreendido, o problema da proteção da Constituição somente poderia ser solucionado pela atuação do Kaiser (LABAND, 1901, p.309; CALDWELL, 1997,

\footnotetext{
${ }^{4}$ Diferentemente do que se pode constatar da tradição constitucional norte-americana (ARAÚJO PINTO; BIGLIAZZI, 2008), na tradição alemã (JACOBSON; SCHLINK, 2000), o Estado é que precede a constituição, e isso tem explicações históricas: o Estado era objeto de um poder e de uma vontade monárquica, que estavam presentes muito antes de se pensar em uma constituição; à Constituição caberia apenas a tarefa de moldar e limitar esse poder - por essência, ilimitado - de uma organização política já existente, de modo que sua legitimidade é apenas derivada da legitimidade do Estado.
} 
p.36). Ele seria o melhor intérprete da "vontade do Estado". ${ }^{5}$ Laband (1901, p.311-312) preocupouse em descrever a Constituição como uma figura normativa (Gesetz) que deve proporcionar a estabilidade e a continuidade do Estado como sua codificação fundamental; mas a ação do Estado pode ter o condão de transformar o seu sentido, mesmo sem a utilização de um mecanismo formal de modificação (LABAND, 1901, p.312; OLIVEIRA, 2011, p.19).

O jurista alemão distingue, então, as figuras da reforma constitucional Verfassungänderung - e da mutação constitucional - Verfassungswandlung (KUBLISCKAS, 2009, p.70) Todavia, Laband vê como um problema o estabelecimento de um hiato entre a "realidade constitucional" e a Constituição formal (PEDRA, 2009, p.108). Mas deve ficar claro que a sua preocupação era apenas de descrever o fenômeno, sem, contudo, proceder a uma teorização mais densa sobre o mesmo (PEDRA, 2009, p.108; VECCHI, 2005, p.53-54).

Assim, Laband (1901, p.314) afirma que a alteração informal da Constituição poderia se dar: (1) pela regulação das leis do Império sobre os elementos centrais do Estado não previstos ou previstos de modo colateral pela Constituição; (2) por modificações dos elementos centrais do Estado por meio de leis do Império que contradizem o conteúdo da Constituição, ${ }^{6}$ e (3) pela alteração dos elementos centrais do Estado por meio de usos e costumes dos Poderes Públicos (SÁNCHEZ URRUTIA, 2000, p.108).

Soma-se a isso o fato de que a regulamentação constitucional era insuficiente, ocasionando diversas questões que tinham que ser complementadas por meio da legislação, como os exemplos dados por Sánchez Urrutia (2000, p.108-109): inexistência de definição da posição política dos ministros do Império, falta de previsão de um procedimento para incorporação de novos territórios à Federação, escassa finança do Império, e vaga e incompleta distribuição de competência entre os Länder e o Império. Sob esse quadro, era comum a modificação da Constituição pela via da elaboração de uma lei.

\footnotetext{
5 "Ce n'est ni le juge, ni l'administrateur, c'est l'Empereur qui est chargé de garder la Constitution de veiller sur elle. C'est à lui qu'incombe la mission de faire observer les principes juridiques qui règlent la législation de lEmpire, dans toute oeuvre législative; il examine dans intérêt de tous les membres, de tous les sujets de l'Empire, si la loi a rempli les conditions constitutionnelles; et il donne au résultat de cette enquête une forme efficace par la promulgation de la loi" (LABAND, 1901, p.325). Tradução livre: "Não é nem o juiz, nem o administrador, é o Imperador que é encarregado de guardar a Constituição e zelar por ela. É a ele que incumbe a missão de fazer observar os princípios jurídicos que regem a legislação do Império em toda obra legislativa; ele analisa o interesse de todos os membros e de todos os sujeitos do Império, se a lei respeita as condições constitucionais; e ele responde a essa indagação de uma forma eficaz pela promulgação da lei”.

${ }^{6}$ Para Laband (1901, p.314), a afirmação de que as leis do Império não podem dispor de modo contrário ao estabelecido pela Constituição representa um princípio político, e não jurídico. O silêncio do texto constitucional acerca do seu caráter supranormativo conduz Laband (1901, p.315) a afirmar a possibilidade de alterações por meio da legislação infraconstitucional. Além do mais, a questão ficaria solucionada pela aplicação de um cânone jurídico, que afirma que lei posterior revoga lei anterior (LABAND, 1901, p. 316).
} 
Laband (1901, p.316) irá considerar, ainda, que uma das mais importantes mudanças constitucionais - inclusive, em desacordo com o texto da Constituição - é a ampliação da faculdade de referendar os atos do Kaiser através da legislação e da prática política. Isso porque a Constituição apenas fazia referência ao poder do Chanceler - como ministro especial - de utilizar tal referendo, colocando-o como o responsável pela ação política estatal. Devido à amplitude dessa função, passou-se a admitir, na prática, que a função de referendo fosse também utilizada pelos administradores do Império. Sánchez Urrutia (2000, p.109) lembra que, em 1879, criou-se legislativamente a figura do Generalvestreter - uma espécie de chefe de Gabinete - que assumia todas as obrigações e as responsabilidades do Chanceler ligadas à administração do Império em casos especiais ou em caso de suplência; mas, na prática, sua nomeação se deu sem que quaisquer dessas circunstâncias tenham ocorrido.

Outra situação de destaque é a Lei de Finanças do Império, que ficou conhecida como Cláusula Frankenstein, acabando por representar uma alteração informal do artigo 38 da Constituição. Esse dispositivo constitucional determinava que o produto das aduanas e dos impostos deveria ser destinado ao abastecimento do caixa do Tesouro Nacional. Com isso, as importações dos Länders era uma faculdade, mas seus ingressos iriam para o caixa do Reich. Em contrapartida, o artigo 70 determinava uma separação entre as finanças imperiais e dos Estados-membros, de modo que qualquer receita adicional que fosse demandada pelo Império deveria provir de contribuições dos Estado-membros (CALDWELL, 1997, p.37-38; DAU-LIN, 1998, p.41-42). No entanto, a Cláusula Frankenstein passou a determinar que as aduanas dos Länders não fossem mais uma instituição facultativa, mas sim, permanente - principalmente o ingresso do tabaco e de bebidas alcoólicas - e que sua receita não fosse mais para o tesouro do Império, mas apenas passasse através dele, transferindo-as para aqueles com um desconto (DAU-LIN, 1998, p.42; LÓPES CADENA, 2007, p.85). Aqui, uma total contradição à Constituição foi firmada, só vindo a ser efetivamente superada pela via de uma reforma constitucional, em 1904, que elevou ao nível constitucional as alterações da lei de finanças (SÁNCHEZ URRUTIA, 2000, p.109; PEDRA, 2009, p.111-112).

Sánchez Urrutia (2000, p.109-110) destaca que Laband assumia que as mudanças informais da Constituição não poderiam ser objeto de controle jurisdicional - já que negava toda a possibilidade de um controle de constitucionalidade jurisdicional, como visto -, defendendo que as leis ordinárias deveriam se harmonizar interpretativamente com a Constituição. Desse modo, em seu pensamento, mesmo a Constituição sendo dotada de força normativa, não possuía uma superioridade hierárquica sobre as leis publicadas pelo Parlamento. Por isso mesmo, as mudanças no campo da realidade poderiam ser solucionadas pelas alterações informais da Constituição, que atualizariam o conteúdo desta, além de manter presente e externalizar a "vontade do Estado". 
Entretanto, como o conteúdo da "vontade do Estado" era conteúdo metajurídico, já que eminentemente político, e, por isso, não havia nada que o Direito pudesse fazer. Aliás, ao jurista, nem ao menos era dada a possibilidade de se atrever a conhecer tal sustância. Dessa forma, a metodologia desenvolvida por Laband atua como fator que o impede de "ver" e conhecer melhor o conceito da mutação constitucional. Ao invés disso, Laband (1901, p.314) limita-se a descrever que mudanças informais existem e que são legitimadas pela "vontade do Estado".

Ao "cegar-se" para uma possível relação entre Direito e Política, Laband se vê impossibilitado de realizar um desenvolvimento teórico mais aprofundado sobre o fenômeno. Além disso, a leitura das condições de possibilidade de sua manifestação acaba por retornar de modo implícito ao antigo princípio monárquico da Constituição prussiana. Sendo assim, Laband está apenas servindo-se do conceito de mutação constitucional para encobrir alterações e/ou descumprimentos da Constituição voltadas exclusivamente ao interesse do Império.

Em outros termos, a mutação serve como um nome novo para legitimar o decisionismo do Kaiser e do Bundesrat, diminuindo os limites constitucionalmente traçados para seu poder, e retirando a força normativa e a condição de supralegalidade da Constituição.

\section{A MUTAÇÃO CONSTITUCIONAL EM GEORG JELLINEK.}

Diferentemente da postura que foi assumida por Laband, afastando da dogmática toda figura metajurídica a partir da assunção de um método extremamente formalista, Verdú (1991, p. xxixxiii) entenderá que aquele deixou - apesar das importantes contribuições - muitas questões não respondidas no campo da Teoria do Estado (VERDÚ, 1991, p.xv). Por isso, entende Jellinek (2000) assumirá a tarefa de sistematizar a Teoria do Estado através de uma construção mais ampla, mas que abriga um dualismo: de um lado, uma doutrina jurídica do Estado, de outro, uma teoria sociológica sobre o mesmo (SANCHEZ URRUTIA, 1993, p.317). Assim, diferente de levar a cabo uma separação e uma "miopia" intencional, Jellinek (2000, p.92-93) se ocupará da realidade histórico-ideológica, ${ }^{7}$ dentro da qual uma teoria político-social e uma teoria jurídica se entrecruzarão.

Verdú (1991, p.xxiii) destaca que a doutrina do direito público ao tempo do Império Guilhermino se olvidou de desenvolver uma resposta crítica ao sistema de poder monárquico,

\footnotetext{
${ }^{7}$ Para Verdú (1991:xvii), Jellinek faz uso dessa metodologia histórica no intuito de não apenas demonstrar ou descrever um fenômeno social, mas antes, explicar suas "formas vitais", isto é o seu surgimento e o seu desaparecimento, bem como suas modificações. Com isso, ele irá analisar se o fim do instituto jurídico foi preservado, ainda que fins novos fossem incorporados, ou se apenas há uma ligação puramente semântica entre o instituto antigo e o novo (VERDÚ, 1991:xvii-xviii).
} 
principalmente devido ao estado de instabilidade política. Assim, seus autores desenvolveram uma distância de segurança - calculada - de tais questões, limitando-se a assumir posturas meramente descritivas, como foi o caso de Laband.

Mas o que isso quer dizer? Jellinek representa um jurista de transição e, por isso, lança um olhar mais preocupado com a questão democrática do que, por exemplo, Laband. Assim, para melhor compreender o pensamento de Jellinek, deve-se, antes, retornar à suas bases.

Da elaboração traçada por Jellinek, os conceitos de reforma e de mutação aparecem sem uma definição mais elaborada, tendo apenas o traço distintivo na figura da "intenção" - ou seja, Jellinek (1991, p.07) entende por reforma constitucional a modificação do texto constitucional através de ações voluntárias e intencionais; e por mutação, as mudanças que independem de alteração no texto constitucional, que são produzidas por fatos, mas sem a consciência da alteração. Aqui, Jellinek delineia uma nova lógica para compreender ambas as figuras, destoando da leitura feita por Laband, segundo a qual o critério estava na existência de um procedimento formal (ou não) para a modificação da norma através do texto.

Desse modo, Jellinek descreve a reforma da Constituição como um movimento que pode assumir três possibilidades: (a) a Constituição pode simplesmente ser ab-rogada; (b) a Constituição pode passar por uma alteração no seu texto; e (c) uma alteração tácita da Constituição pode se dar pela aprovação de leis infraconstitucionais posteriores ${ }^{8}$ (JELLINEK, 1991, p.11; SANCHEZ URRUTIA, 1993, p.319).

Em Jellinek, novamente, fica evidenciado o fato de que sua teoria conceberá, como faz boa parte da doutrina jurídica da época, o Estado como peça chave do direito público. Como consequência, sua “vontade" representará a forma máxima de transformação não apenas do cenário político, mas também do cenário jurídico constitucional, razão pela qual Jellinek (1991, p.09) afirma que não há poder - de fato - que possa impedi-lo de realizar mudanças intencionais - ou seja, reformas - na Constituição.

A questão fica mais delicada, como lembra Jellinek (1991, p.11), quando se atenta para o fato de que a Constituição alemã não traz regulamentações suficientes para o problema e o tratamento jurídico a ser dispensado à reforma constitucional. E dá um exemplo: o artigo $1^{\mathrm{o}} \mathrm{da}$ Constituição refere-se ao território do Império, mas é omisso quanto à presença da Alsacia-Lorena. Assim, apesar de o artigo 20 afirmar que o número de membros do Reichstag ser 382, na realidade

\footnotetext{
${ }^{8}$ A referência histórica trazida por Jellinek (1991, p.11) é a Constituição Norte-Americana, que segundo ele, desde sua promulgação em 1787, não sofreu mudança em sua letra normativa, mas, com a adição das quinze primeiras emendas, tem-se a modificação - até mesmo radical - de alguns conteúdos e conceitos originários do texto. Todavia, essa afirmação é uma confirmação de que Jellinek é incapaz de realizar a separação essencial entre texto e norma constitucional.
} 
são 397, pois ainda devem ser adicionados mais 15 representantes vindos da Alsacia-Lorena, já que tal situação é apenas regulamentada por leis infraconstitucionais, mas que modificam o sentido do texto constitucional originário. Outro exemplo: o artigo 50 da Constituição define que o Imperador é responsável por elaborar as normas sobre correios, mas a Lei de Correios Postais transfere tal competência ao Chanceler com a cooperação do Bundesrat.

Como consequência, Jellinek (1991, p.12) compreende que a Constituição é omissa em diversas situações, levando em conta apenas uma parcela das instituições do Império. Como solução, o Legislativo e o Judiciário precisam, no curso de suas atividades, desenvolver interpretações e definições a fim de ser possível atribuir algum sentido a determinadas passagens dos textos constitucionais (JELLINEK, 1991, p.15-16). Assim, se, por um lado, o Legislador fixa o sentido de determinado texto constitucional ao elaborar uma lei, por outro, o Judiciário, igualmente, assim age no curso da consolidação de sua jurisprudência. Essas interpretações - seja pela elaboração de uma Lei que interprete determinada figura constitucional, seja pela decisão de um Tribunal $^{9}$ - podem acabar fixando sentidos que vão de encontro com o texto constitucional, provocando alterações na sua compreensão.

Já diante de uma mutação constitucional, o texto não sofrerá qualquer alteração, já que a mudança aqui é fática, isto é, há mudança sem o traço da intencionalidade (JELLINEK, 1991, p.11; SANCHEZ URRUTIA, 1993, p.320). A mutação se manifestaria, então, pelas vias: (a) de atos normativos (principalmente leis); (b) pelas mudanças nos costumes constitucionais; (c) por decisões da jurisdição constitucional; e (d) por convenções constitucionais.

Fato é que Jellinek deixou de teorizar com maior profundidade os limites das mutações constitucionais, razão pela qual simplesmente afirma que uma lei ou um regulamento parlamentar pode alterar o sentido da Constituição, principalmente por não haver meios de impugnação dessa lei ou regulamento. Observando a tradição norte-americana, Jellinek (1991, p.23) aponta que a decisão dos tribunais através, principalmente, do controle de constitucionalidade pode provocar uma mutação da Constituição, visto que eles assumem o papel de legisladores negativos e intérpretes da própria Constituição.

\footnotetext{
${ }^{9}$ É importante observar aqui que tanto Laband (1901, p.154-156) quanto Jellinek (1991, p.16) compreendem explicitamente a atividade jurisdicional a partir da teoria desenvolvida por Bülow. Em sua obra Gesetz und Richteramt, de 1885, Bülow apresentará sua defesa do "poder criador de Direito dos juízos". Como destaca Leal (2008, p.48), não se trata de uma mudança de entendimento quanto à obra clássica do mesmo autor de 1868, mas sim, de uma complementação intencional. Bülow declara sua aproximação, assim, ao pensamento de Jhering. Como consequência, direito e poder se equiparam no interior da atividade jurisdicional, ao afirmar que o magistrado deve ser sensivel às necessidades práticas que o direito deve proporcionar (LEAL, 2008, p.52). Para tanto, é necessário romper com a tradição do legalismo e da Escola Histórica, para assegurar o poder dos magistrados controlarem não apenas a "relação processual", como ainda todo o direito vigente (LEAL, 2008, p.60).
} 
A teoria dos "poderes implícitos" do Monarca é, então, um exemplo dessa forma de mutação (JELLINEK, 1991, p.26-27; SANCHEZ URRUTIA, 1993, p.322). É importante destacar que a leitura que Jellinek faz do pensamento de Dicey (1915, p.23-24), quando este descreveu o que chamou de "convenções da Constituição" ou de "moral constitucional" é destoante. Para o jurista inglês, essas convenções, mesmo regulando as condutas dos membros dos poderes públicos, não se encaixam como sendo regras jurídicas, uma vez que não são aplicadas pelo Judiciário. Já o pensador alemão, expressamente reconhece a estas o status de normas jurídicas (JELLINEK, 1991:39; SANCHEZ URRUTIA, 1993:323).

É dessa forma que Jellinek (1991, p.29) irá entender que as modificações como alterações de contextos, de realidades ou de fatos, sem que haja qualquer mudança no texto constitucional, são necessárias. Como bem observou Streck, Cattoni de Oliveira e Lima (2007), Jellinek tentará suplementar a leitura positivista legalista através de uma análise empírica dos processos políticos socais. Com isso, a mutação deixa de ser um problema jurídico e passa a ser um problema político que não pode ser resolvido normativamente. As "forças políticas reais" seriam, então, regidas por normas próprias à revelia de qualquer limitação jurídica (JELLINEK, 1991, p.84).

Para compreender adequadamente a teoria de Jellinek, deve-se voltar para as bases fundantes de sua teoria. Para Ríos (2000, p.13-14), o pensamento de Jellinek descende de um entrecruzar das teorias de Gerber e de Gierke. De Gerber, importante autor do Direito alemão, dirá Ríos (2000, p.15), Jellinek absorve a ideia do método - exclusivamente - jurídico (KELLY, 2003, p.98), que, como enfatizou Triepel (2002, p.176), compreende o direito a partir de si mesmo, preservando sua pureza. Mas o pensamento de Jellinek também sofrerá influências do conceito de Estado como pessoa jurídica e unidade ética. Explica Ríos (2000, p.15-16) que Gerber irá, em seu debate com Albrecht acerca da personalidade do Estado, identificar o Estado como o centro de todo o debate jurídico. É o Estado que converte o povo em comunidade jurídica, sendo o Direito, acima de tudo, uma obra do Estado. Esse mesmo Direito é, ainda, a vontade do Estado e seu poder sobre a sociedade, determinando sua coatividade e obediência. Por isso mesmo, o direito político é estudado por Gerber como tendo a categoria do poder público como sua centralidade.

Para Ríos (2000, p.17), Gerber rejeita a leitura mecanicista/contratualista acerca da sociedade e do Estado, afirmando que a unidade social tem como elemento de coesão uma "força ética comum", que está naturalmente presente no Estado, tendo em vista que este representa a forma social mais alta da humanidade. Ríos (2000, p.17-18) diz, então, que, para Gerber, o direito diz respeito ao modo como essa força ética se exterioriza, o que ele chama de imperium (das 
Herrschen). Tal poder político é, assim, reconhecido como ilimitado - o que não significa afirmar que tal limitação é transferida para seus órgãos. ${ }^{10}$

Stolleis (2001, p.429) afirma que Gerber discordará da teorização feita por Seydel que ficou conhecida como teoria realista, que defende a derrubada de todo conceito do direito político que possa transmitir uma ficção; assim, compreenderá o Estado não como organismo vivo, nem como um sujeito de direito, mas apenas como um conjunto de homens sobre uma porção de terra dominada por uma vontade que lhes é superior (RÍOS, 2000, p.19). Dessa forma, o sujeito do poder do Estado - a quem ele chama de soberano - detém para com seus subordinados uma relação de propriedade. Ora, tal leitura deixa evidenciar um caráter eminentemente civilista do direito público, e uma fusão (ou uma confusão) entre os conceitos de imperium e dominium (RÍOS, 2000, p.20). Gerber descarta tal leitura acerca do direito político por compreendê-la como insuficiente.

Diferentemente, Gierke, no entender de Ríos (2000, p.26-27), compreenderá o Estado como a mais alta forma de comunidade jurídica, mas reconhecerá que ele não é único órgão produtor do direito. Assim, muitas organizações e corporações produziriam autonomamente o direito também em diversos círculos da sociedade. O Estado é uma unidade permanente dotado de vontade, que encerra um povo. Essa vontade é seu poder supremo e vontade soberana, sendo ambos direcionados para um fim: realizar um determinado aspecto essencial da comunidade humana (RÍOS, 2000, p.27). O Estado e o direito estatal são coincidentes, nascem juntos e um pressupõe o outro, formando o chamado "Estado de Direito". ${ }^{11}$ O Estado de Direito, então, é fruto de uma vontade geral, que lhe dota de poder para dominar e controlar a vontade individual no interior da comunidade humana (RÍOS, 2000, p.28).

A partir desses olhares, Jellinek construirá a sua teoria, tendo como ponto inicial a ideia de que o direito é apenas um dos muitos atributos que uma sociedade possui (JELLINEK, 2000, p.61; RÍOS, 2000, p.31). Para Jellinek, o Direito é apenas uma parcela externa - um minimum - de um conjunto normativo maior, a ética social assume como pressuposta a solidariedade dos membros da comunidade, e propõe, a cada membro, a assunção de um fim moral. Tal ética é histórica e cultural, e, por isso mesmo, cambiante. Nesse cenário, Jellinek (2000, p.320-321) vê o direito como um fenômeno psicológico, já que é interno ao homem (VERDÚ, 1991, p.xxviii). ${ }^{12}$

\footnotetext{
${ }^{10}$ Gerber, diz Ríos (2000, p.18), considera que o monarca é um dos muitos órgãos componentes do Estado, e está limitado pelas normas de direito constitucional, ao passo que o Estado, como organismo que cria a constituição, deve ser superior a esta e, por isso mesmo, ilimitado.

${ }^{11}$ Ríos (2000, p.28) destaca que Gierke abandona a leitura de Gerber no sentindo de que o direito é apenas o poder de dominação sobre a vontade de outro.

12 "Georg Jellinek considera o Direito como um fenômeno psicológico, ou seja, um fenômeno interno do homem, o qual faz parte das representações humanas, que está em nossa mente de modo que uma determinação equivale a precisar que parte do conteúdo de nossa consciência é a que designamos com o nome de Direito. Assim, Georg Jellinek afirma que os juízos deduzidos das proposições jurídicas não fornecem o conhecimento de um conteúdo, mas de uma relação. Ensinam-nos a conhecer a relação dos direitos com a norma, de modo que o justo e o injusto
} 
Já a política pode ser definida como a ciência prática do Estado ou a doutrina aplicada, preocupada com o modo pelo o qual o Estado pode alcançar determinados fins (JELLINEK, 2000, p.62-63).

Diante desse quadro, o Estado é tomado como portando duas faces conjuntas, que marcam o pensamento dualista do autor: uma social, outra jurídica (JELLINEK, 2000, p.61; STOLLEIS, 2001, p.441; RÍOS, 2000, p.36). ${ }^{13}$ Através da doutrina social ou sociológica, o Estado preocupa-se com a unidade da sua natureza como construção social; e, pela via da doutrina jurídica, considerase um sujeito de direitos a partir do conceito de corporação, isto é, considera-se uma corporação formada por um povo, dotada de poder de mando originário e assentada dentro de um determinado território (RÍOS, 2000, p.36; VERDÚ, 1991, p.xlx). O estudo do Estado dessa forma mais complexa passa a ser o objeto da Ciência do Estado. Mas, de onde provém a positividade do direito para Jellinek? Ríos (2000, p.28) explica que vem da convicção de sua auto obrigação moral.

É importante destacar, também, que o autor absorve, dentro de sua metodologia, a noção de força normativa do fático, que é amenizada pela a noção de mínimo ético e pela justificação e pela finalidade do Estado (VERDÚ, 1991, p.xxix). Tal posição é consequência da influência da tese de Lassalle de que a "Constituição é a expressão dos fatores e das relações reais de poder" (PEDRA, 2009, p.114). Assim, tal força é, em parte ética, em parte histórica. Explica, então, Pedra (2009, p.115):

Para Georg Jellinek, o Direito é um compromisso entre interesses diferentes e até mesmo opostos. Este compromisso é resultante não apenas das forças dos interesses, mas também do poder social dos interessados neles. Dessa forma, a modificação das forças reais das relações entre os órgãos superiores do Estado se infiltra nas próprias instituições, até mesmo quando não houver sido modificada uma letra da Constituição (PEDRA, 2009, p.115).

Essa força do fato, como força real no interior da normatividade jurídica, produziria evoluções sobre a forma de compreensão da ordem jurídica, sendo inevitável a mudança na norma (VERDÚ, 1991, p.xxxi).

não são predicados aderidos às coisas, não são propriedades, mas sim relações, de sorte que o conhecimento jurídico de um objeto é muito distinto do conhecimento dos fatos reais que o compõem" (PEDRA, 2009:114).

13 "In terms of scholarly strategy, however, both the two-side theory and the doctrine of legal validity are completely sound. It was certainly plausible to separate empirical and normative research into individual areas while at the same time continuing to appreciate the way that they dovetail with each other" (STOLLEIS, 2001, p.443) Tradução livre: "Em termos de estratégia acadêmica, entretanto, tanto a teoria dualista quanto a doutrina da validade jurídica são completamente harmônicas. Era claramente possível separar a pesquisa empírica e a normativa em áreas individuais, enquanto, ao mesmo tempo, continuava a apreciar como elas se encaixavam". 
É preciso destacar, como faz Verdú (1991, p.lx), que Jellinek não procedeu a uma teorização independente do conceito de constituição apartado do conceito de Estado. ${ }^{14}$ Em Jellinek, portanto, a Constituição está ligada a um princípio ordenador que irá limitar a situação dos membros dentro do Estado (LÓPES CADENA, 2007, p.82). Além disso, a Constituição traz normas que irão sustentar a estrutura do Estado.

Essa Constituição pode manifestar-se na forma de um mero poder de fato, ou, no caso dos Estados Modernos, pode assumir a forma de uma ordem jurídica (VERDÚ, 1991, p.xi). ${ }^{15}$

Novamente, então, aparece a influência de Lassalle no pensamento de Jellinek (VERDÚ, 1991, p.lxii-1xiii), entendendo-se por Constituição a redução a termo das forças políticas em uma sociedade (LASSALLE, 2009, p.07). Assim, os problemas do direito constitucional são antes políticos que jurídicos (LASSALLE, 2009, p.40), de modo que sua forma escrita, como Constituição formal, não será nunca capaz de abarcar toda a complexidade da "constituição real", e, um dia, entrará em colapso (LASSALLE, 2009, p.33) e sucumbirá.

Assim, as Constituições rígidas, como o caso da alemã imperial, não poderiam evitar que um direito constitucional não escrito se desenvolvesse, já que o substrato abstrato do direito, o mundo do Sollen, é dependente de uma conexão com a realidade, o mundo do Sein. Diferentemente, no caso das constituições flexíveis, haveria uma maior potencialidade de adaptação às necessidades e à realidade (VERDÚ, 1991, p.xiii).

Dessa forma, a figura que Jellinek chamará de mutação constitucional é, na realidade, a confirmação dessa influência do real sobre o normativo; mas, com isso, há um preço a se pagar: a força normativa da constituição acaba por se curvar para a força normativa do fato (JELLINEK, 1991, p.07).

Analisando seu próprio contexto social, Jellinek perceberá que a implantação do sistema constitucional imperial de 1878 como condição para a sua unificação acabou por gerar insegurança e incerteza jurídica, uma vez que a Constituição apenas se sobrepunha às confederações anteriores e aos seus regimes sem que houvesse qualquer mecanismo de adaptação (SANCHEZ URRUTIA, 1993, p.314).

Além disso, era evidente a hegemonia política prussiana nesse cenário. O Legislativo bicameral era composto pelo Bundesrat e pelo Reichstag. O primeiro órgão era composto por delegados de cada Estado-membro, mas não seguia uma lógica igualitária, pois a Prússia detinha o direito a mais cadeiras que os demais. Já o Reichstag tinha seus membros eleitos pelo sufrágio

\footnotetext{
${ }^{14}$ A verdade é que tal mérito virá apenas no trabalho de Schmitt e, depois, no de Loewenstein, que separarão a ideia e a terminologia de uma Teoria da Constituição - Verfassungslehre (VERDÚ, 1991, p.lx).

${ }^{15}$ Há, então, uma conexão entre o conceito de Jellinek de constituição e aquele já traçado por Aristóteles sob a forma de politea (JELLINEK, 2000, p.457; VERDÚ, 1991, p.lxiii).
} 
universal masculino. Mas não havia uma regra de proporcionalidade que, devido ao fato de a Prússia ter a população equivalente a quase dois terços do Império, conseguia compor a maioria dos assentos. Além disso, o rei prussiano era também o imperador e, em geral, o chanceler imperial era o presidente do Conselho da Prússia (SANCHEZ URRUTIA, 1993, p.314-315).

A Constituição de 1878 era rígida e qualquer reforma poderia ser barrada pelo Bundesrat se houvesse pelo menos 14 votos contrários, e, dada a superioridade da Prússia, quaisquer alterações formais da constituição estavam submetidas ao seu consentimento (SANCHEZ URRUTIA, 1993, p.315).

A partir disso, Jellinek acusa o Bundesrat de fazer, permanentemente, frente à Constituição do Império - criticando, inclusive, a postura de Laband ao ignorar tal quadro em sua obra - e, com isso, destituir a força normativa da própria constituição pela sobreposição de suas "forças políticas reais" (JELLINEK, 1991, p.30; SANCHEZ URRUTIA, 1993, p.316).

Ora, para Jellinek (1991, p.5-6), a Constituição é que tem força normativa, e, portanto, deve ser hierarquicamente superior às leis emanadas do Legislativo ou aos atos vindos do Executivo, condicionando a atividade de ambos. A rigidez da Constituição que deveria funcionar como um mecanismo de sua própria proteção, era insuficiente. Um exemplo é o problema da existência de seções secretas de deliberação no Reichstag, que, a despeito de serem proibidas pela Constituição, estavam previstas nos regimentos parlamentares (JELLINEK, 1991, p.17-18; SANCHEZ URRUTIA, 1993, p.318). Ora, a princípio, por violar a Constituição, tais deliberações deveriam ser nulas, mas acabavam sendo confirmadas pelo Bundesrat e pelo Kaiser. Logo, diante da falta de um mecanismo de controle de constitucionalidade, acabavam por ganhar validade jurídica.

A fraqueza da construção teórica jellinekiana é denunciada, inclusive, por outro teórico alemão da mutação constitucional, Konrad Hesse (2009), ${ }^{16}$ que defende a impossibilidade de uma solução jurídica para problemas que ensejam uma influência da realidade sobre a norma e aponta uma falha no esclarecimento jurídico e no estabelecimento de limites para a mutação constitucional. Segundo o jurista:

Uma teoria jurídica da mutação constitucional e de seus limites só seria possível com o sacrificio dos pressupostos metódicos básicos do positivismo: a estrita separação entre "Direito" e "realidade", assim como o que constitui sua consequência, a rejeição de quaisquer considerações históricas, políticas e filosóficas do processo de argumentação jurídica. Com tais pressupostos resultava impossível resolver juridicamente o problema da influência da "realidade" sobre o

\footnotetext{
${ }^{16}$ Mais uma vez, alertamos que o objetivo do presente texto, não é analisar as propostas de Hesse (ou mesmo de qualquer outro autor que tenha contribuído para o desenvolvimento da teoria da mutação constitucional), mas sim, reconstruir o contexto de fala de Laband e Jellinek, na crise do Império alemão. Para outros autores, um novo texto deverá ser proposto e elaborado.
} 
conteúdo das normas. Fica-se, assim, em descrições empíricas de casos importantes que, sem embargo precisamente por causa do seu caráter empírico confere ao resultado alcançado um peso semelhante ao da demonstração de uma lei física (Hesse, 2009, p.157).

\section{CONCLUSÃO}

Após desenvolvermos as considerações acima, buscamos realizar um estudo histórico do conceito de mutação constitucional e o modo como foi assumido por seus defensores, fica clara a carência, ainda, de uma compreensão afinada com aquisições teóricas trazidas por uma teoria hermenêutica contemporânea.

Assim, no tópico 02, partimos da demarcação do contexto histórico no qual Laband se encontrava inserido para poder vislumbrar que sua teoria acerca da mutação constitucional - uma vez que sustenta uma dicotomia rígida entre o que seja Direito e o que seja Política, que atua como fator que o impede de "ver" e conhecer melhor o conceito da mutação constitucional - fará com que Laband (1901, p.314) se limite a descrever que mudanças informais existem e que são legitimadas pela "vontade do Estado". Contudo, acaba, assim por "cegar-se" , ficando impossibilitado de realizar um desenvolvimento teórico crítico e mais aprofundado sobre o fenômeno.

Portanto, o conceito de mutação constitucional, em Laband, serve apenas para encobrir alterações e/ou descumprimentos da Constituição voltadas exclusivamente ao interesse do Império. Em outros termos, a mutação é um nome novo, que legitima o o Kaiser e o Bundesrat, diminuindo os limites constitucionalmente traçados para seu poder, e retirando a força normativa e a condição de supralegalidade da Constituição, como poderia criticar Hesse (2009).

Em um segundo momento, ao se voltar os olhos para a proposta teórica de Jellinek acerca do conceito de mutação constitucional, vê-se que a dicotomia norma $\mathrm{x}$ fato, deve ser solucionada pela atribuição de uma posição hierarquicamente superior às leis emanadas do Legislativo ou aos atos vindos do Executivo, condicionando a atividade de ambos.

Assim, a rigidez da Constituição que deveria funcionar como um mecanismo de sua própria proteção, era insuficiente principalmente porque não há um mecanismo de controle de constitucionalidade, de modo a proteger a normatividade constitucional do primado dos fatos que acabavam por angariar validade jurídica.

Para finalizar, é fundamental consignar que as teorizações tanto de Laband quanto de Jellinek estão situadas no contexto das discussões da Escola Alemã de Direito Público, bem no período de 
transição entre os séculos XIX e XX. Assim, elas estão ligadas a uma separação absoluta entre o

Direito e a realidade, de maneira que a mutação seria fruto da imposição de uma modificação havida no âmbito da realidade ao Direito.

No entanto, essa proposta não mais se sustenta, uma vez que, ao restringir-se a uma análise empírica dos fenômenos políticos e sociais, não se consegue lidar normativamente com o reconhecimento das influências das realidades sociais no Direito, de modo que a mutação constitucional finda por figurar como uma saída para justificar o prevalecimento da vontade do Estado sobre quaisquer outras forças constitutivas de Direito.

THE CONSTITUTIONAL CHANGE IN GERMAN EMPIRE'S PUBLIC LAW: LABAND AND JELLINEK'S CONTRIBUTIONS

Abstract: Since Brazilian constitutional law continues to make use of the concept of constitutional change, mainly through the STF, it is fundamental to verify the correctness of the use of such theoretical instruments. The present study aims to investigate the historical roots of the concept of constitutional change from its emergence in the historical context of the German Empire. From this, we will be able to identify that the use of the concept by Brazilian theory and practice distanced themselves and divorced from the original construction of German constitutional law. Therefore, in Brazil, the constitutional change has its meaning emptied and transformed only into a rhetorical tool by the STF.

Keywords: constitutional change (Verfassungswandlung); German Constitutional Law; History of Law.

\section{LA MUTACIÓN CONSTITUCIONAL EN EL DERECHO PÚBLICO DEL IMPERIO ALEMÁN: CONTRIBUCIONES DE LABAND Y JELLINEK}

Resumen: Una vez que el derecho constitucional brasileño continúa haciendo uso del concepto de mutación constitucional, principalmente por el STF, resulta fundamental verificar la corrección del empleo de tal instrumental teórico. El presente estudio tiene por objetivo investigar las raíces históricas del concepto de mutación constitucional a partir de su surgimiento en el contexto histórico del Imperio alemán. A partir de eso, vamos a poder identificar que la utilización del concepto por 
la teoría y la práctica brasileña se distancian y se divorcian de la construcción original del derecho constitucional alemán. Por lo tanto, en Brasil, la mutación constitucional tiene su sentido vaciado y transformado sólo en una herramienta retórica por el STF.

Palabras clave: Mutación Constitucional; Derecho Constitucional alemán; Historia del Derecho.

\section{REFERÊNCIAS BIBLIOGRÁFICAS}

ARAÚJO PINTO, Cristiano Paixão; BIGLIAZZI, Renato. História Constitucional Inglesa e NorteAmericana: do surgimento à estabilização da forma constitucional. Brasília: UnB, 2008.

CAENAGEM, R. C. van. Uma Introdução Histórica ao Direito Constitucional Ocidental. Tradução de Alexandre Vaz Pereira. Lisboa: Caloutre Gulbenkian, 1996.

CALDWELL, Peter C. Popular sovereignty and the crisis of German Constitutional Law: the Theory and Practice of Weimar Constitutionalism. London: Duke University Press, 1997.

CARVALHO NETTO, Menelick de. A sanção no procedimento legislativo. Belo Horizonte: Del Rey, 1992.

DAU-LIN, Hsü. Mutación de la Constitución. Tradução de Pablo Lucas Verdú e Cristian Förster. Bilbao: Instituto Vasco de Administración Pública, 1998.

DICEY, Albert Venn. Introduction to the study of the law of the constitution. 6. ed. London: Macmillan, 1915.

JACOBSON, Arthur J.; SCHLINK, Bernhard. Constitutional Crisis: The German and the American Experience. In: JACOBSON, Arthur J.; SCHLINK, Bernhard (Org.). Weimar: a jurisprudence of crisis. Tradução de Belinda Cooper. Berkeley/London: University of California, 2002. p.1-39.

JELLINEK, Georg. Reforma y mutación de la Constitución. Tradução de Christian Förter. Madrid: Centro de Estúdios Constitucionales, 1991.

JELLINEK, Georg. Teoría General del Estado. Tradução de Fernando de los Ríos. México: Fundo de Cultura Económica, 2000. [Política y Derecho].

JOUANJAN, Olivier. Présentation. In: JOUANJAN, Olivier (Org.). Figures de l'État de droit: Le Rechtsstaat dans 1'histoire intellectuelle et constitutionnelle de l'Allemagne. Strasbourg: Press Universitaires de Strasbourg, 2001.

JOUANJAN, Olivier. Une Histoire de la Pensée Juridique em Allemagne (1800-1918): Idéaçlisme et Conceptualismo chez les Juristes Allemands du XIX ${ }^{\mathrm{e}}$ Siècle. Paris: PUF, 2005.

KELLY, Duncan. The State of the Political: conceptions of politics and the State in the thought of Max Weber, Carl Schmitt and Franz Neumann. Oxford: Oxford University, 2003. 
HESSE, Konrad. Limites da Mutação Constitucional. In: Temas Fundamentais de direito constitucional. São Paulo: Saraiva, 2009.

KUBLISCKAS, Wellington Márcio. Emendas e mutações constitucionais: análise dos mecanismos de alteração formal e informal da Constituição Federal de 1988. São Paulo: Atlas, 2009.

LABAND, Paul. Il diritto del bilancio. Tradução de Clemente Forte. Milano: Giuffrè, 2007.

LABAND, Paul. Le Droit Public de l'Empire Allemand, v. II. Tradução de G. Gandilhon. Paris: Giard \& Briére, 1901.

LASSALLE, Ferdinand. A essência da Constituição. Tradução de Aurélio Wander Bastos. 9. ed. Rio de Janeiro: Lumen Juris, 2009.

LEAL, André Cordeiro. Instrumentalidade do processo em crise. Belo Horizonte: Mandamentos, 2008.

LÓPES CADENA, Carlos Alberto. Mutación de los Derechos Fundamentales por la Interpretación de la Corte Constitucional Colombiana: Concepto, Justificación y Límites. 2007. Tese (Doutorado em Direitos Humanos) - Instituto de Derechos Humanos" Bartolomé de las Casas", Universidad Carlos III, Madrid.

MAIA, Paulo Sávio Peixoto. A "Luta pelo Método" na República de Weimar. Revista CEJ, Brasília, a. XIV, n. 49. abr./jun. 2010. p. 51-58.

OLIVEIRA, Larissa Pinha de. Parâmetros hermenêuticos da mutação constitucional. 2011. Dissertação (Mestrado em Direito) - Departamento de Direito da Pontifícia Universidade Católica do Rio de Janeiro, Rio de Janeiro.

PEDRA, Adriano Sant'Ana. Teoria da Mutação Constitucional: limites e possibilidade das mudanças informais da constituição a partir da teoria da concretização. 2009. Tese (Doutorado em Direito do Estado) - Pontifícia Universidade Católica de São Paulo, São Paulo.

RÍOS, Fernando de los. Prólogo del Traductor. In: JELLINEK, Georg. Teoría General del Estado. Tradução de Fernando de los Ríos. México: Fundo de Cultura Económica, 2000. p.13-52. [Política y Derecho].

SANCHEZ URRUTIA, Ana Victoria. La Fuerza de La Constitución y La Constitución de La Fuerza. Revista Española de Derecho Constitucional. a. 13, n. 37, ene./abr., 1993. p.313-325.

SANCHEZ URRUTIA, Ana Victoria. Mutación Constitucional y Fuerza Normativa de La Constitución: una aproximación al origen del concepto. Revista Española de Derecho Constitucional. a. 20, n. 85, ene./abr., 2000. p.105-135.

STOLLEIS, Michael. A History of Public Law in German: 1800-1914. Oxford: Berghan Books, 2001.

TRIEPEL, Heinrich. Law on the State and Politics. In: JACOBSON, Arthur J.; SCHLINK, Bernhard (Org.). Weimar: a jurisprudence of crisis. Tradução de Belinda Cooper. Berkeley/London: California Press, 2002. p.176-188. 
VECCHI, Cristiano Brandão. A mutação constitucional: uma abordagem alemã. 2005. Dissertação (Mestrado em Teoria Geral do Estado e Direito Constitucional) - Departamento de Direito, Pontifícia Universidade Católica do Rio de Janeiro, Rio de Janeiro.

VERDÚ, Pablo Lucas. Curso de Derecho Político. Madrid: Tecnos, 1984. v. VI.

VERDÚ, Pablo Lucas. Estudios Preliminar. In: JELLINECK, Georg. Reforma y mutación de la Constitución. Tradução de Christian Förter. Madrid: Centro de Estúdios Constitucionales, 1991. p.xi-lxxix.

VERDÚ, Pablo Lucas. O Sentimento Constitucional: aproximação ao estudo do sentir constitucional como um modo de integração política. Tradução de Agassiz Almeida Filho. Rio de Janeiro: Forense, 2006.

Trabalho enviado em 20 de janeiro de 2019

Aceito em 17 de março de 2019 